\title{
DIÁLOGO SOCRÁTICO EN LOGOTERAPIA
}

\section{Socratic dialogue in Logotherapy}

\author{
Alejandro Khaled Salomón Paredes*
}

\begin{abstract}
Resumen
En este artículo se elabora un detallado marco aplicativo del llamado Dialogo Socrático, como la principal herramienta psicoterapéutica de la Logoterapia, profundizando en la metodología, la actitud del terapeuta y los campos de intervención sobre la persona. Se incluyen numerosos ejemplos de abordajes, preguntas clave y señalamientos. Se acude a autores como V. Frankl, E. Lukas, J. Fabry, E. Martínez, entre otros, en relación a lo que esta forma de conversación terapéutica representa en aras de movilizar la libertad de cada consultante.
\end{abstract}

Palabras clave: Dialogo, psicoterapia, logoterapia, libertad, responsabilidad, encuentro.

\begin{abstract}
In this article a detailed application framework called Socratic Dialogue as the main psychotherapeutic tool of Logotherapy, delving into the methodology, the attitude of the therapist and the fields of intervention is made about the person. Numerous examples of approaches, key questions and remarks are included. It goes to authors such as V. Frankl, E. Lukas, J. Fabry, E. Martinez, among others, in relation to which this form of therapeutic conversation is in order to mobilize the freedom of each client.
\end{abstract}

Keywords: Dialogue, psychotherapy, speech, freedom, responsibility, meeting.

\footnotetext{
* Docente de la Facultad de Psicología y Humanidades de la Universidad Femenina del Sagrado Corazón.
} Director del Centro Psicoterapéutico Logos (CPL). asalomonp@unife.edu.pe 


\section{EL DIÁLOGO SOCRÁTICO EN LA LOGOTERAPIA}

"La verdadera sabiduría está en reconocer la propia ignorancia”. Sócrates

El Diálogo Socrático fue desarrollado por el filósofo Sócrates en la antigua Grecia, cuando mediante preguntas y cuestionamientos buscaba la reflexión del interlocutor con el fin de que considere como válidos otros puntos de vista, diferentes del sostenido, ampliando el conocimiento y "dando a luz" una verdad (Martínez, 2012). Sin embargo es probable que ni el mismo Sócrates intuyera las profundidades aplicativas que su estilo de relación y dialogo aportaría al mundo de la psicoterapia, en especial a aquellas escuelas que se basan en el encuentro, en la relación Yo - Tú, en la no interpretación del mundo del consultante y en el respeto más elevado por su libertad personal.

Es así que no nos remitiremos a Sócrates, sino a Viktor E. Frankl (1901 - 1997) quien habló de un dialogo en un sentido socrático, Frankl (2002), como parte fundamental de su método psicoterapéutico: la Logoterapia. Esta es, a grandes rasgos, una propuesta psicoterapéutica que se centra en que la persona se haga consciente de su propia libertad de decisión, respondiendo por si misma ante su vida y asumiendo la angustia que la libertad misma conlleva. Tal responsabilidad se relaciona al hallazgo y vivencia de valores, a estar abierto al mundo (Scheler, 1957), de forma auténtica, encontrándole sentido a la vida.

Concretamente en logoterapia, el diálogo socrático es un estilo de encuentro psicoterapéutico que puede darse entre dos o más personas y que busca por medio de preguntas, señalamientos, descripciones y el elemento más importante, la relación misma, ayudar al consultante a tomar conciencia de su libre voluntad (Frankl, 2007), invitándolo a dar respuesta por si mismo ante lo que la vida le plantee.

El dialogo socrático, como su nombre lo indica, está inspirado en los encuentros que Sócrates sostenía con sus conciudadanos de Grecia, buscando confrontarlos con sus supuestas "verdades" con el fin de demostrar su ignorancia (Martínez, 2012). Si bien Sócrates no es conocido por ser psicoterapeuta, su intención y método sirven a la logoterapia en el sentido de que una vez que se hace consciente la libre voluntad, la persona pueda actualizar sus posibilidades de ser responsable, expandiéndolas por medio de la decisión, hacia una existencia más auténtica y más plena de sentido.

En palabras de Fabry (Fabry, 2009. P. 25): “el diálogo socrático es el instrumento que el facilitador emplea con más frecuencia en la búsqueda de sentido. Este diálogo nos pone en encuentro con nuestro núcleo saludable, el espíritu, a fin que podamos hacer uso de sus recursos".

Es importante aclarar que este método socrático se aplica también en otras áreas como la pedagogía, con formas y propósitos diferentes, que no son objeto de este artículo.

El diálogo socrático reúne una serie de aspectos metodológicos y actitudinales que constituyen la base vincular del proceso logoterapéutico. Podemos entonces hablar de:

- Actitud socrática

- Preguntas socráticas

- Señalamientos socráticos.

A continuación profundizaremos cada aspecto metodológicamente, detallando los procesos con ejemplos del diálogo en consultas con diversas personas, así como preguntas clave que pueden servir de guía al lector interesado.

\section{¿CÓMO PREGUNTAR? LA ACTITUD SOCRÁTICA}

Aquí se contiene la clave para un adecuado encuadre logoterapéutico, ya que implica la puesta en forma de una actitud personal frente a sí mismo y al consultante, donde predominan la autenticidad y la disposición amorosa de entrega al otro. Al hablar de disposición amorosa no exageramos al decir que la persona del terapeuta ha de tener el "corazón abierto" ante la persona del consultante, es decir, aceptarlo y acogerlo en su sufrimiento y su neurosis, confirmándolo no solo en su aquí y ahora sino en sus posibilidades de ser (Bruzzone, 1994, citado por Martínez, 2012). 
Como señala E. Lukas (Lukas, 2004 P. 115) refiriéndose a Frankl: “...lo importante de una técnica de conversación no es la técnica en sí, sino el espíritu con que se aplica. La técnica no servirá de nada mientras se ciña exclusivamente a prescribir recetas, pero su resultado será milagroso si está impregnada con el espíritu del amor".

El amor es entonces el sustento del cómo preguntar y de cómo señalarle algo al otro, en sí, de todo el vínculo terapéutico. Incluso cuando la pregunta resulta confrontadora, o el señalamiento irónico o frustrante, si el amor está presente, serán escuchados con los oídos del espíritu para movilizar la autoconciencia y la responsabilidad del consultante.

La relación terapéutica se sustenta en el Yo - Tú (Buber, 1994), en el encuentro sin prejuicios ni interpretaciones acerca de la otra persona. Dos seres que se encuentran uno junto al otro, donde el amor moviliza a llegar a ser una mejor versión de sí mismos (Martínez, 2012), tanto de la persona del terapeuta como de la persona del consultante.

Si hay disposición amorosa hay aceptación, tolerancia, paciencia y respeto respecto a los ritmos y tiempos del consultante y del proceso en sí. Este respeto se fundamenta en la actitud fenomenológica antes referida, donde se está abierto a la experiencia siempre nueva del encuentro, junto a una persona siempre nueva y única. Esta forma fenomenológica de dialogo representa el abordaje más respetuoso de la libertad en cada persona.

Según Martínez (Martínez, 2012. P. 76) la importancia de la relación terapéutica radica en que:

- Brinda una base segura para disparar nuevas captaciones de la realidad, es decir, cambios profundos de actitud con menos miedo.

- Facilita el cambio por el sentido que atrae y no por la presión del terapeuta

- Facilita la manifestación de los recursos personales a partir de la relación, permitiendo que los supuestos riesgos que mantienen a la persona cerrada a la experiencia sean disuadidos.

- Moviliza la expresión del autodistanciamiento a través de las circunstancias que plantea la relación.

- Ayudan a expresar la autotrascendencia, fomentando así la capacidad de abrirse íntimamente, dejarse ver y ver a los demás.

- Permite validar la experiencia del consultante aceptando que lo que el consultante expresa es su verdad y por tanto respetable.

- Permite generar vínculos de compromiso que favorezcan el proceso de cambio.

El factor clave en este vínculo amoroso entre dos personas es la confianza, siendo esta uno de los objetivos principales del encuentro terapéutico. La persona del terapeuta aprende a confiar en la persona del consultante, con todo lo que trae y en su ser posible; mientras que el consultante, al ir confiando en el terapeuta, se va permitiendo salir al mundo, al encuentro del que tiene al frente, dejándose ver con todo y la angustia de dejarse ver.

\section{Ingenuidad e ironía.}

El dialogo socrático, al buscar confrontar al consultante con su actitud inauténtica e irresponsable, utiliza la ironía y la ingenuidad (Lukas, 2004, Martínez, 2012) a manera de punta de lanza que hinca las bases de la estructura mental de la persona, removiendo sus cimientos hasta autodistanciarse y hacer consciencia de lo limitante de la actitud y el sinsentido en el modo de ser, por medio de la captación de algo valioso en su vida, lo que lo pone "en jaque" respecto a su postura actual. El estilo irónico del diálogo socrático es paradójicamente no confrontacional, ya que no pone al terapeuta como rival del consultante, resistente a lo que este trae como su experiencia. Más bien lo acoge reconociendo sus incoherencias y preguntándole con el fin de buscar claridad. Como sabemos, la claridad es señal de que la luz se empieza a esparcir.

Aquí presentamos un ejemplo de un abordaje confrontacional y otro con ingenuidad e ironía socráticas. Se trata de una persona con alcoholismo que no acepta la enfermedad:

\section{Confrontacional:}

$\mathrm{T}$ (terapeuta): ¿y no crees que con tu actitud estás causando mucho sufrimiento a tu familia? ¿No has pensado en tus hijos? 
C (consultante): eso es lo que me dicen, pero nadie comprende que yo tengo todo bajo control. Están sufriendo en vano.

\section{Ingenuidad e ironía socráticas:}

T: No entiendo algo, ¿cómo es que si me dices que amas a tus hijos por sobre todo en el mundo, sigues bebiendo y viéndolos sufrir con eso? La verdad, no me queda claro; acláramelo por favor, y de paso aclárate tú también.

C: (silencio y mirada fija a un lado) No lo sé, no lo había visto así, pero siento pena cuando los veo sufrir.

El completamiento de frases ayuda al consultante a conectarse con aquello que evita ver o con aquellos recursos que se encuentran latentes, ampliando la autoconsciencia. Son preguntas abiertas que invitan a la persona a completar con aquello que siente sobre sí misma o que ya sabe de sí misma pero le cuesta observar o aceptar.

Algunos ejemplos de completamiento son:

T: ¿Esto significa que tú...?, ¿o que el...?

T: ¿cómo te hace sentir eso?, ¿cómo un qué...?

$\mathrm{T}$ : entonces ¿temes sentirte como un qué...?

T: ¿y quién es alguien que fracasa?, ¿un qué...?

$\mathrm{T}$ : entonces es como si en ti hubiera un recurso de...

T: al verlo así es como si tuvieras la capacidad de...

\section{La mayéutica.}

Es el arte de dar a luz la verdad del consultante (Martínez, 2012). Cuando la relación terapéutica está cimentada y se ha establecido un vínculo de confianza y apertura, las preguntas se tornan más incisivas y provocadoras, confrontando al consultante con su modo de ser inauténtico, buscando que de la confusión del momento surja la claridad que ilumine la conciencia, ayudándolo a transitar la angustia propia de su responsabilidad.

Según Restrepo (Restrepo, 2001, en Martínez, 2012. p. 67) "La mayéutica socrática es una forma de poner en práctica la modulación de la actitud y consiste en una discusión del consultante sobre sí mismo con la ayuda del terapeuta, quien, como facilitador, presenta preguntas provocadoras e incisivas sobre lo que el consultante sostiene en virtud de una pasividad o actividad malsanas; en otras palabras, consiste en extraer el conocimiento del propio interlocutor".

Ejemplo:

T: ¿para qué miras constantemente hacia afuera por la ventana cuando te pregunto esto?

C: (silencio)

T: ¿ah?

C: ¡no lo sé! ¿Supongo que para no mirarte a los ojos no?

T: Ok, y ¿qué riesgo no quieres correr? ¿Qué pasaría si me miras?

C: que veas lo que no quiero ni yo mismo mirar

$\mathrm{T}:$ ¿a qué te refieres?

C: a mi temor, a mi cobardía, a mi debilidad

\section{LAS PREGUNTAS SOCRÁTICAS}

El diálogo socrático implica un encuentro fenomenológico, donde el logoterapeuta busca facilitar la conciencia de la propia libertad personal del consultante, sin intervenir aconsejando, orientando ni sugiriendo y sin interpretar ni inferir a partir de lo ya conocido (otras personas). Aquí nos remitimos a la Epoché de Edmund Husserl donde se busca suspender todo juicio o certeza respecto a la realidad de un objeto (Husserl, 2011). Por tanto si lo que se busca es la libertad y responsabilidad el abordaje debe estar centrado en preguntar, describir y señalar, siguiendo el método fenomenológico ampliamente trabajado en los enfoques humanistas - existenciales. Como señala Bruzzone (2008) la pregunta supone un sujeto capaz de pensar y de avanzar en la consciencia a través de la misma.

Es así que desde la fenomenología las preguntas socráticas incluyen siempre un aspecto no interpretativo de aproximación al consultante, para lo cual se utilizan el ¿Qué?, el ¿Cómo? y el ¿Para qué?, como preguntas básicas (Martínez, 2012).

\section{¿Qué preguntar?}

En logoterapia se busca que la persona despliegue sus recursos espirituales (lo específicamente humano) Frankl (2003), principalmente el autodistanciamiento 
y la autotrascendencia. Para esto se hace uso de las preguntas fenomenológicas (no interpretativas, sino más bien descriptivas) ¿qué?, ¿quién?, ¿cómo?, ¿dónde?, ¿cuándo? y ¿para qué?, estando atento a la respuesta del consultante, para así poder hacer otra pregunta o señalamiento que favorezca el proceso de dar a luz su verdad.

\section{Diálogo socrático y autodistanciamiento.}

Respecto a esta capacidad espiritual señala Frankl (Frankl, 2007. P. 23): "En virtud de tal capacidad, el hombre es capaz de tomar distancia no solo de una situación, sino también de sí mismo. Haciéndolo, realmente toma posición respecto a sus propios condicionamientos y determinantes somáticos y psicológicos. Visto así, una persona es libre de moldear su propio carácter y el hombre es responsable por aquello que pueda hacer de sí mismo". Esta capacidad específicamente humana nos permite ubicarnos a una distancia fecunda (Frankl, 2007) para monitorearnos, confrontarnos, vernos a futuro con optimismo y tomar las riendas de nuestra vida. En palabras de Martínez (Martínez, 2011. P 15): "El autodistanciamiento es la capacidad específicamente humana de tomar distancia de sí mismo y monitorear los propios procesos emotivo - cognitivos. Es la manifestación de la autoconciencia que terapéuticamente es bastante útil y se expresa a través de la autocomprensión, la autoproyección y la autorregulación".

A partir de esto iremos explorando, mediante ejemplos extraídos de procesos psicoterapéuticos, los usos del diálogo socrático para el despliegue de tales capacidades, teniendo en cuenta las preguntas clave que movilizan lo espiritual tanto para abordar las restricciones que implanta lo psicofísico sobre la libertad personal como la búsqueda de sentido en la vida.

La autocomprensión es la capacidad del hombre de tomar conciencia de sí mismo, es decir, la autoconciencia. Esta capacidad es, según Frankl (2003), espiritual, por ser específicamente humana y permite clarificar la existencia personal: La existencia no se puede objetivar, sino únicamente elucidar. Pero solo es elucidable porque ella misma se comprende a sí misma: la existencia goza de autocomprensión, Frankl (2003).
Para Martínez (Martínez, 2011 P. 16): "la autocomprensión permite al hombre monitorearse, encontrarse consigo mismo, verse a sí mismo en situación y en sus circunstancias particulares...es la posibilidad de descubrir y asumir su participación en lo que le acontece, de identificarse y afirmarse a sí mismo a través del autoconocimiento". También podemos llamar a esta capacidad autodescubrimiento (Fabry, 2009).

La autocomprensión puede ser desplegada mediante el encuentro logoterapéutico a través del diálogo socrático, buscando ampliar la autoconciencia respecto a:

1. Las emociones.

2. Los significados.

3. Los miedos.

4. Las vivencias.

5. Las estrategias de afrontamiento (pasividades y actividades) (Frankl, 1994).

6. Los recursos personales (espirituales).

Autocomprensión de las emociones.

Muchas veces las personas llegan a consulta sin permitirse sentir plenamente o sin tener claridad respecto a lo que sienten. Esto puede ser parte de un mecanismo neurótico que se sustenta en la inautenticidad para eludir la angustia que por naturaleza la vida conlleva por ser el hombre un ser responsable. Por eso es crucial lograr claridad y comprensión respecto a la propia emocionalidad, ya que las emociones son el correlato subjetivo de los valores que hay en el mundo (Martínez, 2011), allá afuera, en la vida de la persona.

A continuación se describe un extracto de un diálogo socrático orientado a la autocomprensión emocional:

$\mathrm{T}$ (terapeuta): Dime ¿qué es lo que te ocurre?

C (consultante): no me siento bien, me siento infeliz, inseguro de mi mismo

T: ¿y qué es lo que sientes con todo eso, emocionalmente?

C: me da pena, me siento triste

$\mathrm{T}$ : ¿y cómo es sentirte triste?

C: me pongo a llorar, me encierro en mi cuarto, me siento abatido. 


\section{Otro ejemplo:}

T: veo que mueves tus manos y tus piernas, ¿qué es lo que sientes?

\section{C: no lo sé}

T: ahí si tenemos un problema, ¿si tú no lo sabes, quién?

C: (risas) Bueno, siento ansiedad

T: ¿qué te pone ansioso?

\section{Otro ejemplo:}

T: Me parece curioso que justo ahora al hablar de esto quieras irte al baño, ¿qué sientes?

C: nada, solo quiero ir al baño

$\mathrm{T}$ : solo los muertos no sienten, y yo no estoy hablando con un muerto, algo has de estar sintiendo

C: me siento incómodo

T: ok, ¿y esa incomodidad, con qué emoción se relaciona?, ¿qué sientes?

C: siento miedo

Algunas preguntas clave pueden ser:

- ¿Qué es lo que sientes cuando ocurre eso?

- ¿Qué es sentirte mal?

- ¿Cómo sientes esa pena?

- ¿Dónde sientes más tu miedo?

- ¿Cómo no quieres sentirte?

- ¿Qué sientes de saber que lograste afrontarlo?

- ¿Y todo esto tan valioso frente a ti qué te hace sentir?

\section{Autocomprensión de los significados.}

Los significados son las interpretaciones que hace la persona acerca de la realidad, de sus experiencias, de sí mismo, de los demás y de su vida. Un significado es una atribución cognitiva (Martínez, 2011) que forma parte de la estructura mental y cosmovisión que tiene una persona, por tanto, es una especie de guía o referente para la existencia. Por ejemplo, si alguien fue engañado por su pareja a los catorce años y esto conllevó una vivencia dolorosa y frustrante, es probable que para esta persona, ya de adulta, las relaciones de pareja signifiquen peligro, algo doloroso que no vale la pena vivir, que las parejas engañan, o que no es bueno abrir el corazón, etc. Es la interpretación que la persona le da a la experiencia, desde el dolor y la frustración. Lo sano es que este sufrimiento, al ser plenamente aceptado y vivido de paso con el tiempo al hallazgo del sentido de la situación, enriqueciendo la existencia. Lo insano es que se estanque cognitiva y emocionalmente. Con esto la persona no se da permiso de sentir, de relacionarse, de conocer a alguna otra persona, de dar y recibir amor, etc.

Si los significados son negativos se vuelven limitantes e impiden el hallazgo del sentido de las situaciones que se viven y de la vida en general. Si por el contrario son positivos se vuelven posibilitadores, ya que facilitan la captación de valores y sentido (Díaz Del Castillo, conversación personal, 2011). También es posible que los significados puedan tornarse positivos a partir de que la persona se deje tocar por un valor. Cuando un valor es descubierto, intuido o sentido, pueden alterarse los esquemas mentales a favor de la autenticidad, la coherencia y la libertad.

El diálogo socrático busca que el consultante se autodistancie y autocomprenda respecto a los significados que sostienen su percepción de la realidad, descubriendo si le son útiles o funcionales para una vida con sentido. Algunos ejemplos de abordaje logoterapéutico con el dialogo socrático pueden ser:

T: ¿qué te ocurre con tu esposo?

C: me duele y me da cólera cuando le hablo y no me mira, sigue mirando el periódico o la televisión.

T: ¿y qué significa esto para ti?, ¿significa que el qué..., o que tú qué...?

C: significa que no me quiere, que no le importo.

$\mathrm{T}$ : ¿tienes esa sensación con otras personas también?

C: la otra vez mientras yo te hablaba miraste tu celular y me sentí igual

T: ¿quieres decir que no eres importante para mí?

C: así me siento

$\mathrm{T}$ : ¿y cómo sabes qué es lo que yo siento por ti? ¿Tienes algún don especial que no me hayas contado?

C: (risas) bueno no, la verdad es lo que yo imagino.

\section{Otro ejemplo:}


$\mathrm{C}$ : tengo miedo de decidirme

T: ¿qué pasa si te decides?, ¿a qué te arriesgas?

$\mathrm{C}$ : a que me salga mal, a fallar

T: ¿y qué significa para ti fallar?, ¿Quién es alguien que falla?

C: un inútil, un fracasado

T: me pregunto ¿cuántas cosas quisieras hacer y no haces para no sentirte un inútil fracasado?

\section{Otro ejemplo:}

C: no me animo a terminar con ella, me cuesta

T: ¿qué significaría para ti terminar con ella?

C: soledad

T: ¿y qué significa para ti estar solo?

$\mathrm{C}$ : no tener a nadie

T: ¿y para qué quieres tener a alguien?, no me hablas de ella en particular. ¿Qué significa para ti estar solo?

C: no me siento completo, como que solo no podría vivir. Necesito de alguien siempre.

T: ¿y cuál es el precio que tienes que pagar por tener esa muleta constante?

$\mathrm{C}$ : me siento esclavizado

Algunas preguntas clave:

- ¿Qué significa esto para ti?

- ¿Significa que tu...?

- ¿Qué quiere decir eso para ti?

\section{Autocomprensión de los miedos.}

El miedo es parte de la existencia humana inevitablemente. El miedo nos advierte, nos mueve, para hacernos sentir vivos y confrontarnos con nuestra propia vida. Es decir, el miedo nos acompaña siempre, ya que constantemente la vida, con su naturaleza incierta, amenaza lo que para nosotros es valioso e importante (Martínez, 2011). Sentir miedo es el aviso de que algo puede ser doloroso o frustrante, ante la pérdida de un valor. Puedo sentir miedo cuando mi integridad o mi salud se ven amenazadas, o algún ser querido, o algo en lo cual encuentre sentido, como una relación, un trabajo, un proyecto, etc. Existencialmente, en el terreno de la responsabilidad, el miedo es llamado angustia, como el estrechamiento de las posibilidades del ser, como el miedo a ser libre y asumir la propiedad de la vida. La responsabilidad es elección, la cual implica riesgo, y el riesgo está cargado de angustia. Entonces el ser humano se angustia porque es libre (May, 2000). En este sentido el dialogo socrático apunta a movilizar la autoconciencia respecto a los miedos que paralizan, por lo general relacionados a actitudes neuróticas de evitación de la responsabilidad, ayudando al consultante a posicionarse frente a lo que le ocurre y aceptando la angustia como posibilidad de cambio, decidiendo.

Algunos ejemplos de dialogo socrático para lograr autocomprensión respecto a los miedos y la angustia son:

T: ¿y qué pasaría si lo dejas?

$\mathrm{C}$ : lo he pensado, pero me da mucho miedo hacerlo

T: ¿qué te da miedo?

$\mathrm{C}$ : que realmente se vaya y no vuelva

T: ¿y qué pasaría si se va y no vuelve?, ¿a qué le temes realmente?

C: a quedarme sola

T: ¿y qué pasaría si te quedas sola?, ¿a qué le temes en el fondo?

$\mathrm{C}$ : a tener que vérmelas por mi misma

$\mathrm{T}$ : ¿y a qué le temes si te las tienes que ver por ti misma?

C: a que no pueda, a que no me salgan las cosas bien. ¡Me siento tan insegura, tan dependiente!

Algunas preguntas clave:

- ¿Qué te da miedo?

- ¿Cómo es ese miedo?

- ¿Qué te angustia?

- ¿Qué pasaría si lo hicieras?

- ¿A qué te arriesgas si te decides?

- ¿Qué te impide asumirlo?

- ¿Qué te cuesta aceptar de todo esto?

- ¿Qué no quieres que te ocurra?

Autocomprensión de las vivencias.

Las vivencias son experiencias que marcan en lo emocional y cognitivo (Martínez, 2011), constituyéndose luego en la forma cómo la persona se vive, cómo se ubica en el mundo, cómo se siente y cómo se ve. Mientras las experiencias son temporales 
y pasan, las vivencias son atemporales, permaneciendo en el devenir de la persona. Una vivencia negativa puede condicionar la existencia, donde la persona se bloquea en su libertad y conciencia y no se expresa, restringida por significados limitantes que alimentan la vivencia. Por ejemplo, un joven que de niño era sobre exigido por su padre en lo académico, donde sentía que no era reconocido en su esfuerzo y nunca alcanzaba las expectativas del padre ni de otras personas, puede tener la vivencia de incapacidad, es decir, sentirse un incapaz, un bueno para nada que no puede lograr ningún buen resultado, con lo que se inhibe de tomar decisiones, para evitar el fracaso de no ser como esperaban que fuera, lo cual le activaría la vivencia.

En este contexto el diálogo socrático busca que el consultante se autocomprenda respecto a cómo se siente consigo mismo y cómo es que aprendió a sentirse así, descubriendo las formas en que en el presente evita que el mundo le toque el "moretón", ya sea luchando o huyendo (Frankl, 2007), impidiéndose ser auténtico por miedo a la angustia de enfrentar la vida.

A continuación un ejemplo de diálogo socrático para autocomprensión de las vivencias.

T: ¿qué es lo que sientes cuando eso pasa?

C: me siento muy ansioso, siento miedo

$\mathrm{T}$ : ¿y cómo te sientes en ese momento frente a esas personas? ¿Cómo un qué...?

C: como un ratoncito, como alguien pequeñito, poco importante

T: ¿y qué haces para no sentirte un ratoncito?

C: entro por la puerta de atrás, para que nadie me vea. Trato de pasar inadvertido.

\section{Otro ejemplo:}

T: ¿Para qué gritas? Puedo escucharte perfectamente a esta distancia.

$\mathrm{C}$ : ¡es que quiero que me escuches, que me respetes!

T: entiendo, ¿y qué pasa si no me gritas?

C: creo que no me vas a tomar en cuenta

T: uhm ahora entiendo para qué te muestras agresivo y me gritas. ¿Qué pasa si no te escuchan entonces?, ¿cómo no te quieres sentir?
C: (con lágrimas y mirada perdida) no se otra forma de lograr sentir que estoy, porque siento que nadie me hace caso. No quiero sentir que no existo, que no soy importante para nadie.

Algunas preguntas clave:

- ¿Qué evitas sentir?

- ¿Cómo te sientes cuando eso ocurre?

- ¿Te sientes como un...?

- ¿Cómo has aprendido a sentirte como un...?

- ¿Qué haces para no sentirte un...?

Autocomprensión de las estrategias de afrontamiento (pasividades y actividades).

Frankl (2008) refiere que existen dos reacciones neuróticas por excelencia: la huida respecto a los síntomas y la lucha contra estos. A estas estrategias de afronte ante la vida las llamó respectivamente "pasividad y actividad incorrectas", Frankl (2008), ya que implican la no aceptación de lo que viene ocurriendo en la existencia, sobre todo en lo emocional y cognitivo, aunque implican también negar aquello que es en el mundo del consultante. Por ejemplo, alguien puede huir de su miedo o de aquello que le genera miedo (como las fobias) o pelearse a muerte con sus pensamientos o deseos (como en las obsesiones) para eliminar la angustia y el sufrimiento. Ambas estrategias implican no aceptar la realidad que angustia, invirtiendo energía en distensionar el organismo psicofísico (Martínez, 2011).

Si bien las pasividades y actividades incorrectas son reacciones neuróticas, en logoterapia entendemos a la neurosis como una función de cuidado (Martínez, 2011), según Heidegger el Sorge (en Martínez, 2011), el cuidado del ser sobre su propia existencia, en este caso cuidando la identidad psíquica y el equilibrio emocional. En la neurosis se da un cuidado extremo, donde la persona no se permite vivir la angustia ni la adversidad, inhibiendo la responsabilidad y la libertad mismas, con lo que hablamos de un modo inauténtico de ser (Martínez, 2012). Frankl (2008) también nos habla de "pasividad y actividad justas", que implican la aceptación de los síntomas con humor y la desviación de la atención de los síntomas una vez aceptados hacia objetivos con sentido en la vida, respectivamente.

El autodistanciamiento como autocomprensión de las pasividades y actividades incorrectas moviliza la 
autorregulación, es decir, el dominio de sí mismo y la toma de responsabilidad por parte del consultante.

En el diálogo se debe indagar al consultante de forma incisiva, confrontándolo con su propia conciencia respecto a lo realmente importante y valioso para él. En esta parte se utiliza con más énfasis la pregunta ¿para qué?

\section{Ejemplo:}

T: ¿Para qué sigues con él si estás sufriendo? No te entiendo

C: No lo sé, quizá porque con él me siento segura. Ya hemos hablado de mis miedos y mi inseguridad.

T: Entonces, ¿para qué sigues con él? ¿Cómo consigues sentirte? ¿Qué pasaría si terminas la relación? ¿A qué te arriesgas?

C: sigo con él para no valerme por mi misma. Tengo miedo a quedarme sola.

T: ¿toda tú está coherente con ese modo de ser, o hay alguna parte desde donde quisieras algo diferente?

C: bueno si, en parte quisiera poder decirle que ya basta sin este miedo tan paralizante.

Algunas preguntas clave:

- ¿Y qué haces para no sentirte así?

- ¿Cómo haces para protegerte en esas situaciones?

- ¿Sientes que huyes o que luchas frente a esto?

- ¿De qué forma afrontas la situación?

- ¿Cuál es el precio que tienes que pagar por este modo de ser?

- ¿Para qué actúas de esa manera?

- ¿Para qué haces esto?

\section{Autocomprensión de los recursos personales.}

Viktor Frankl nos propone una visión del ser humano esperanzadora y propulsora del cambio, con una idea de persona dinámica y siempre en posibilidad de ser diferente por medio de su decisión. En palabras del mismo Frankl (Frankl, 2007. P. 23): "Y la persona es fundamentalmente capaz de hacer frente a toda morbilidad psicofísica; de lo contrario yo no podría ejercer de psiquiatra, sería inútil".. La persona no es su enfermedad, ni su condición, y finalmente se encuentra en posibilidad de afrontar, de dar cara a su situación psicofísica y existencial. Esto gracias a los recursos que le son constitutivos: las capacidades del espíritu, la conciencia, la voluntad, la responsabilidad y la libertad que se encuentran siempre posibles (salvo en condiciones de restricción biológica irreversible, como es el caso de un accidente cerebro vascular, o un traumatismo craneal severo, un estado de coma vegetativo o un retardo mental profundo). Tales recursos mientras son posibles se encuentran como potencia en lo que Frankl (2003) llama inconsciente espiritual, esperando actualizarse en un acto de libertad, como puede ser un momento de autodistanciamiento, autoconsciencia y autodeterminación.

El diálogo socrático debe explorar el inconsciente espiritual, el depósito de recursos latentes, para que el consultante los haga conscientes. Las preguntas han de orientarse a tomar mayor consciencia del accionar actual (casi siempre reacciones automáticas, estrategias de afrontamiento incorrectas) y hacia las acciones que la persona puede realizar como actos de responsabilidad, de autodominio y libertad luego de haberse auto comprendido. Aquí ya hablamos de autorregulación.

La Autorregulación es la capacidad específicamente humana de distanciarse y regular los propios procesos afectivos y emotivos, reconciliarse con lo psicofísico o de oponerse a sí mismo si es preciso (Martínez, 2012). Es en pocas palabras, la capacidad de hacerse cargo de sí mismo, de dominarse, de apropiarse de la personalidad y ejercerse a pesar de las disposiciones internas.

Algunos ejemplos de autocomprensión de los recursos personales y autorregulación:

C: Hoy no tenía fuerzas ni para levantarme de la cama

T: ¿Y cómo has hecho para venir aquí?

C: no lo sé, bueno venir aquí se supone que me ayudará a estar mejor

T: me alivia que haya en tu mejoría una motivación para levantarte de la cama. ¿En qué otros aspectos de tu vida puedes tener una motivación así? ¿Qué otras cosas te motivan a levantarte de la cama? 


\section{Otro ejemplo:}

C: he descubierto que haciendo "la ley del hielo" a mi familia me protejo, me cuido de que me hieran.

T: ¿Te funciona? ¿Te llegas a sentir del todo bien con ese modo de ser?

C: pues no, por un rato puede ser, pero luego vuelvo a lo mismo. Cedo y sigo esperando de ellos que me hagan caso para no sentirme poco importante para ellos.

T: ¿Qué quisieras hacer entonces con ese "moretón" que tienes y que cuidas tanto?

C: creo que no estoy siendo clara con ellos, solo les digo superficialmente las cosas. Ahora quiero decirles lo que en verdad siento

T: uhm ese es un riesgo

C: si, estoy dispuesta a afrontarlo. Ya estoy cansada.

Algunas preguntas clave:

- ¿Qué quisieras hacer ahora?

- ¿Qué está a tu alcance hacer habiéndote hecho consciente de todo esto?

- ¿Cómo hiciste para hacerte cargo de eso?

- ¿Cuál es la opción que tiene más sentido para ti?

Por otra parte el autodistanciamiento puede ser también Autoproyección, lacapacidadespecíficamente humana de verse a futuro diferente de cómo se viene siendo (Martínez, 2011), con esperanza, con una visión que amplía las posibilidades del ser y brinda sentido al momento presente.

Cuando una persona se encuentra enferma en lo emocional y psíquico puede restringirse en esta capacidad, impidiéndose la visión esperanzadora, con lo que se estanca existencialmente y deja de percibirse como un ser siendo, quedando como un soy. En palabras de Frankl (Frankl, 2014 P. 94) "el neurótico es aquel que cambia la forma de percibirse: de un poder ser siempre diferente, por un ser siempre de la misma manera".

En este sentido el diálogo socrático buscará el despliegue de tal recurso espiritual para que el consultante se conecte con esa dosis de esperanza tan necesaria para que la voluntad asome por entre las grietas de la neurosis. Hay que movilizar las posibilidades del ser siendo y mirar al horizonte existencial con optimismo, tomando en cuenta qué hay en el presente del consultante que le puede brindar sentido a su vida y no logra captar. Las preguntas van dirigidas al proyecto, al futuro, confrontando al consultante consigo mismo en el aquí y ahora.

Algunos ejemplos pueden ser:

T: Dime ¿cómo te ves de aquí a seis meses de terapia?

$\mathrm{C}$ : bueno, espero sentirme mejor

T: ¿y qué sería sentirte mejor?

C: sentirme no tan triste todo el tiempo, pero no sé cómo lograrlo

T: bueno para eso estás aquí. Desde ya es muy terapéutico que logres verte a futuro diferente y mejor.

\section{Otro ejemplo:}

C: me veo igual

$\mathrm{T}$ : te entiendo, debe ser difícil observar el futuro con un presente tan duro

C: así es, no puedo verme distinto

$\mathrm{T}$ : ¿quisieras poder verte distinto?

C: claro, pero no sé si lo lograría

T: a ver, probemos, ¿cómo te gustaría verte? Usa un poco tu imaginación

C: no lo sé, más auténtico, menos obsesivo, como que más libre

$\mathrm{T}$ : y en este momento ¿quisieras arriesgarte a imaginar ese futuro? A ver cierra los ojos y déjate llevar por ese querer estar mejor...

Algunas preguntas clave:

- ¿Cómo te ves de aquí a...?

- ¿Cómo te gustaría verte?

- ¿Cómo quisieras sentirte?

- ¿Qué necesitas hacer ahora para lograr eso?

\section{Dialogo socrático y autotrascendencia}

La autotrascendencia es la capacidad específicamente humana de ir más allá de sí mismo al encuentro con el mundo. En palabras de Frankl (Frankl, 1997 p. 51): "Porque ser hombre significa 
estar orientado hacia más allá de sí mismo, hacia algo o alguien... un trabajo que realizar o un ser humano al cual amar". La esencia del hombre es su autotrascendencia (Frankl, 1997). De ahí que la neurosis y los trastornos psíquicos impliquen un ensimismamiento, un no salir, un no ir más allá de sí. De esta forma los valores y el sentido en la vida pasan desapercibidos, siendo el sentido una "percepción cognitiva y afectiva de valores" (Martínez, 2011). El ser humano entonces se realiza en la medida en que se autotrasciende (Frankl, 2003), en que sale y va más allá de sí y capta lo valioso que hay en su vida, en su mundo, en su existencia que es afuera de sí. Es así que, según E. Martínez (20011), la autotrascendencia como capacidad espiritual puede a su vez manifestarse a través de la diferenciación, la afectación y la entrega.

La Diferenciación es la capacidad del hombre de ver al Tú y distinguirse del resto, para poder encontrarse con otro ser humano. Es la capacidad de estar junto a otro ente espiritual (Martínez, 2011). Si el consultante no logra diferenciarse, distinguirse en su unicidad, en su singularidad e irrepetibilidad, es decir, en la responsabilidad que le corresponde, no logrará vincularse de forma genuina con otro, con un Tú (Buber). El diálogo socrático ha de orientarse a que el consultante se diferencie de los demás, con preguntas dirigidas a su unicidad y a la conciencia de la alteridad, confrontando lo propio con lo ajeno a fin que distinga que le corresponde a su existencia.

Algunos ejemplos:

C: no me siento plena con mi carrera, como que no me llenara. Eso me genera sentimientos de culpa y confusión. Me deprimo luego.

T: ¿de qué te sientes culpable?

C: de no estar haciendo lo correcto

T: ¿Lo correcto? ¿Quién eligió estudiar psicología y trabajar en eso?

C: bueno, yo. Mi madre y mi abuela querían que estudie derecho.

T: ¡Ah! Entiendo. Y para ti ¿tiene sentido lo que realizas? ¿Sientes que te aporta vida a ti y a otros?

C: si claro, siento que me enriquece, me gusta mucho ayudar a esas personas.

T: me queda más claro. Tú le encuentras sentido a lo que haces, pero no tu mamá ni tu abuela. ¿Le encuentras relación a esto con la culpa de la que me hablabas?

C: pues sí, pero ellas no son yo. Creo que ahora comprendo un poco más mi sentir y mi situación. Y me siento más coherente también.

\section{Otro ejemplo:}

C: Me frustra tanto que ella no quiera ir conmigo, me hace sentir que no le importo.

T: ¿y sabes qué siente ella?, ¿por qué no quiere ir contigo?

C: me dice que no le gustan ese tipo de reuniones

T: ¿y tú estás esperando que a ella le guste exactamente lo mismo que a ti? (actitud irónica)

Algunas preguntas clave:

- ¿Qué esperas del resto?

- ¿Qué pasa si no esta persona no es como tú?

- ¿Cuál es la diferencia fundamental entre tú y esta otra persona?

- ¿Esperas que los demás sean como tú quieres?

- ¿Qué te hace ser único?

- ¿Qué sentido tiene para ti ser alguien único?

Otra manifestación de la autotrascendencia es la capacidad de dejarse tocar por los valores, de resonar afectivamente en su presencia. Es la llamada Afectación (Martínez, 2012), que implica estar abierto al mundo, salir e ir más allá de sí mismo al encuentro del sentido, que espera afuera, en la vida misma. Los estados de ensimismamiento relacionados a las neurosis y trastornos restringen esta capacidad autotrascendente, bloqueando la captación de lo realmente significativo para el consultante. Al estar continuamente dentro de sí mismo no logra salir para ver lo que hay fuera, perdiendo posibilidades de hallar sentido a su vida y a lo que le acontece. La labor socrática implica entonces movilizar al consultante hacia "afuera", a encontrarse y vibrar emocionalmente con personas, tareas, proyectos, experiencias y todo aquello que viene pasando desapercibido y que es posibilidad de sentido en su vida. Es precisamente un asunto de percepción, de estar abiertos para poder ver los valores, y sentirlos. Las preguntas han de referirse al sentir respecto a lo que hay frente al consultante, apelando a la emocionalidad, a las sensaciones, al 
eco que resulta de conectar con lo valioso, con lo que construye vida para sí y para los demás.

\section{Ejemplo:}

T: Veo que hay lágrimas en tus ojos cuando me hablas de tu familia. ¿Qué es lo que sientes?

C: Tristeza. Me duele verlos así.

T: Me imagino cuan valiosos son para ti, que te entristece su situación. ¿En qué sentido su sufrimiento tiene que ver contigo?

C: con todo esto, esta adicción que no quiero reconocer

T: Entonces, $\measuredangle$ Tiene sentido para ti no hacer nada al respecto, con todo y lo que sientes en este momento?

Algunas preguntas clave:

- ¿Qué sientes frente a esto?

- ¿Cómo resuena en ti esto?

- ¿Sientes que esto te emociona?

- ¿Qué hay tan valioso allá afuera que no estás viendo?

Según Viktor Frankl podemos encontrar sentido a la vida en el donarnos al mundo en una acción concreta: una tarea, un servicio, una ayuda, un trabajo. A este camino hacia el sentido lo llamó valores de creación (Frankl, 2003), que implica un acto de Entrega, donde de alguna forma me olvido de mí y me doy a otro, desinteresadamente, sin buscar satisfacción alguna. En palabras del fundador de la logoterapia (Frankl, 2007 P. 107): "solo en la medida en que el hombre se aparta de sí mismo en cuanto deja de lado los intereses y la atención egoístas consigue un modo auténtico de existencia" haciendo alusión a la capacidad específicamente humana de autotrascendencia. En este sentido el diálogo se orientará a movilizar al consultante hacia la realización de algo concreto en su vida, a partir de preguntas que apunten a la decisión de abrirse al mundo donde los valores lo esperan.

Preguntas clave:

- ¿Sientes que esto puede ayudar a otras personas también?

- ¿De qué forma esto puede construir vida para otros?

- ¿Esto que haces tiene sentido para ti?
- ¿De qué manera puedes brindarte a otros con esta experiencia?

- ¿Qué otras personas podrían enriquecerse con esto que te pasa?

- ¿Esto que quieres hacer es solo para ti o implica a alguien más?

\section{LOS SEÑALAMIENTOS SOCRÁTICOS}

El diálogo socrático implica una forma de encuentro donde no solo hay un ir y venir de preguntas y respuestas mecanizadas, sino una actitud de entrega y disposición mutuas que se va construyendo con el pasar del tiempo, y que parte indefectiblemente de la actitud del terapeuta. Sin embargo, aunque pareciera que las preguntas cobran especial relevancia (ya que es el consultante el llamado a responder), también son de vital importancia los señalamientos, es decir, intervenciones del terapeuta en las cuales pone énfasis en algunos aspectos del vínculo que se va dando y que llaman su atención. Aquí podemos encontrar:

\section{Lo no verbal.}

Los aspectos no verbales son señalados por el terapeuta de forma fenomenológica, sin interpretar lo que señala, buscando claridad por parte del consultante respecto a su propio ser.

Ejemplos de señalamiento de lo no verbal:

T: veo que tus ojos brillan cuando me hablas de esto.

$\mathrm{T}$ : me parece curioso que justo quieras ir al baño cuando te pregunto sobre esto.

T: noto que no me miras a los ojos.

La naturalidad.

Aquí el terapeuta señala, desde su propio vivenciar en la terapia, algún aspecto natural de lo humano que el consultante no logra captar. Precisamente quien está neurótico bloquea el fluir natural de la vida, en sus esfuerzos por no vivir la angustia que la vida misma conlleva.

Algunos ejemplos de señalamiento de la naturalidad:

C: Me siento tan triste, realmente deprimido.

T: ¿Hace cuánto tiempo que te ocurrió esto que me cuentas? 


\section{C: tres semanas}

$\mathrm{T}$ : bueno, me alivia que esto te esté pasando. Me preocuparía que tras tres semanas no estés triste por algo tan doloroso para ti.

\section{Otro ejemplo:}

$\mathrm{C}$ : siento miedo a mostrarme en realidad con lo que me pasa frente a todos.

$\mathrm{T}$ : te entiendo. Y mira, me preocuparía si no tuvieras reparo en los demás y si no cuidarás eso que es tan valioso para ti. Quizá ya no estarías aquí.

\section{Las incoherencias.}

Señalar una incoherencia es poner en descubierto la sana confrontación entre la personalidad neurótica y la persona que busca el cambio y se orienta a valores, es decir, entre la restricción y el recurso libre. A partir de señalar una incoherencia (con la respectiva confusión que se genera) vendrá la claridad para la elección consciente y responsable, para intencionarse hacia el sentido (Lukas, 2004). Pueden usarse la ironía y el humor para lograr el autodistanciamiento respecto al modo de ser actual (Frankl, 2008).

Algunos ejemplos:

C: no puedo decir lo que siento frente a otras personas. Me siento una débil, una tímida.

T: No te entiendo bien, yo noto que me hablas y me estás diciendo lo que sientes. ¿Exactamente a qué te refieres?

Otro ejemplo:

C: Soy un completo inútil, así me siento.

T: bueno es obvio que viniste. Y llegaste a tiempo. Creo que hay que revisar eso de ser un completo inútil.

Otro ejemplo:

T: no entiendo cómo si tus hijos son lo más importante en tu vida (como tú me lo señalas), sigues consumiendo alcohol mientras los ves sufrir con esto.

\section{Captación de valores.}

El logoterapeuta puede señalar las posibilidades de valor encerradas en la situación y en la vida misma (Lukas, 2004) del consultante, a fin de movilizar la afectación y la captación y realización del sentido. Esto sin inducir al consultante u orientarlo a los valores que el terapeuta considere, recordando que el diálogo socrático es un encuentro fenomenológico, respetuoso del proceso de cada quien.

\section{Ejemplo:}

C: Mira, yo no me siento un adicto. Pero mi familia no lo ve así y está sufriendo.

T: O sea, entiendo que llegas a captar su dolor

$\mathrm{C}$ : $\mathrm{Si}$, claro que si.

T: entiendo que tu familia es realmente valiosa en tu vida. ¿Entonces tendría sentido para ti cambiar ciertos hábitos aunque tú no los consideres negativos?

C: creo que sí.

Otro ejemplo:

$\mathrm{T}$ : ¿y cómo te sientes con tu modo de ser actual?

$\mathrm{C}$ : cómoda, no tengo que hacer las cosas, las hacen por mí.

T: claro, pero ¿toda tú está coherente con ese modo de ser? o ¿hay alguna pequeña parte quizá que quiera algo diferente?

C: bueno si, por algo estoy aquí

T: ¡Exacto! Entiendo entonces que por un lado evitas hacer las cosas y con eso evitas ser responsable, pero... ¿de qué te estás perdiendo con todo esto?, ¿qué estás dejando pasar en tu vida?, ¿cuál es el precio que estás pagando por esta comodidad?

C: (entre lágrimas) pues que muchas cosas quiero hacerlas por mí misma, como venir aquí. Eso sería realmente importante. No me siento libre, siento que dependo de todos. Realmente me estoy perdiendo muchas cosas valiosas.

\section{El terapeuta en persona.}

Durante la terapia el terapeuta puede permitirse expresar directamente lo que siente en relación al otro, favoreciendo el autodistanciamiento del consultante respecto a su modo de ser inauténtico (Martínez, 2011) o la autotrascendencia manifestada en diferenciación y afectación. Esta afectividad no es actuada sino más bien genuina y espontánea. Por supuesto esto da pie al autodistanciamiento del propio terapeuta respecto a aquello que siente frente al otro. 
Algunos señalamientos:

$\mathrm{T}$ : te voy a ser sincero, cuando te levantaste e hiciste ese ademán sentí miedo. Me dieron ganas de alejarme de ti. Me pregunto a cuántas otras personas les pasará lo mismo.

T: te diré que cuando te veo en esa actitud me dan ganas de sacudirte y decirte ¡despierta! Me pregunto con quienes más te pasa algo parecido.

$\mathrm{T}$ : a veces siento como que no estuvieras. Se me dificulta verte. ¿Te pasa esto con otras personas?, ¿como que no te vieran?

El diálogo socrático representa una alternativa psicoterapéutica centrada en una actitud fenomenológica, en el encuentro siempre abierto hacia la otra persona, sostenido en el más elevado respeto por la unicidad, dignidad y libertad personales. En este sentido nos propone una rehumanizante forma de aproximarnos y vincularnos con el Tú, y de actualizar lo libre de cada quien, hacia la autenticidad, la responsabilidad y la apertura a los valores, es decir, a vivir una vida plena de sentido.

\section{REFERENCIAS}

Bruzzone, D. (2008). Pedagogía de las alturas. Logoterapia y educación. México: LAG.

Buber, M. (1994). Yo y Tú. Argentina: Nueva Visión.

Fabry, J. (2009). Señales del camino hacia el sentido. México: LAG.

Fecha de recepción: 21 de abril del 2014

Fecha de aceptación: 22 de Mayo del 2014
Frankl, V (2014). En el principio era el sentido. Argentina: Paidós

Frankl, V. (2008). Teoría y terapia de las neurosis. España: Herder.

Frankl, V. (2007). Logoterapia y análisis existencial. España: Herder.

Frankl, V. (2003). Ante el vacío existencial. España: Herder.

Frankl, V. (2003). Psicoterapia y existencialismo. España: Herder.

Frankl, V. (2002). La voluntad de sentido. España: Herder.

Frankl, V. (1997). Psicoanálisis y existencialismo. México: FCE

Husserl, E. (2011). La idea de la fenomenología. España: Herder.

Lukas, E. (2004). Logoterapia. Argentina: Paidós.

Martínez, E. (2011). Los modos de ser inauténticos. Colombia: Manual Moderno.

Martínez, E. (2012). El dialogo socrático en la psicoterapia. Colombia: Aquí y ahora.

May, R. (2000). El Dilema del hombre. Colombia: Gedisa.

Scheler, M. (2004). El puesto del hombre en el cosmos. Argentina: Losada.

Varios. (2007). Frankl por definición. Argentina: San Pablo. 